\title{
Multi Element Telescope for Imaging and Spectroscopy (METIS) coronagraph for the Solar Orbiter mission
}

\author{
Ester Antonucci ${ }^{\mathrm{a}}$, Silvano Fineschi ${ }^{\mathrm{a}}$, Giampiero Naletto ${ }^{\mathrm{b}}$, Marco Romoli $^{\mathrm{c}}$, Daniele Spadaro ${ }^{\mathrm{d}}$, \\ Gianalfredo Nicolini ${ }^{\mathrm{a}}$, Piergiorgio Nicolosi ${ }^{\mathrm{b}}$, Lucia Abbo ${ }^{\mathrm{a}}$, Vincenzo Andretta ${ }^{\mathrm{e}}$, \\ Alessandro Bemporad $^{\mathrm{a}}$, Frédéric Auchère ${ }^{\mathrm{p}}$, Arkadiusz Berlicki ${ }^{\mathrm{f}}$, Roberto Bruno ${ }^{\mathrm{n}}$, \\ Gerardo Capobianco $^{\mathrm{a}}$, Angela Ciaravella ${ }^{\mathrm{q}}$, Giuseppe Crescenzio ${ }^{\mathrm{a}}$, Vania Da Deppo ${ }^{\mathrm{g}}$, \\ Raffaella D'Amicis ${ }^{\mathrm{n}}$, Mauro Focardi ${ }^{\mathrm{c}}$, Fabio Frassetto ${ }^{\mathrm{b}}$, Peter Heinzel ${ }^{\mathrm{f}}$, Philippe L. Lamy ${ }^{\mathrm{r}}$ \\ Federico Landini ${ }^{\mathrm{c}}$, Giuseppe Massone ${ }^{\mathrm{a}}$, Marco A. Malvezzi ${ }^{\mathrm{h}}$, J. Dan Moses ${ }^{\mathrm{i}}$, Maurizio Pancrazzi ${ }^{\mathrm{c}}$, \\ Maria-Guglielmina Pelizzo, Luca Poletto, Udo H. Schühle ${ }^{\mathrm{m}}$, Sami K. Solanki ${ }^{\mathrm{m}}$, Daniele, Telloni ${ }^{\mathrm{a}}$, \\ Luca Teriaca $^{\mathrm{m}}$, Michela Uslenghi ${ }^{1}$
${ }^{a}$ INAF - Astrophysical Observatory of Torino, (Italy), INAF - ${ }^{b}$ University of Padova, (Italy); ${ }^{c}$ University of Florence , (Italy); ${ }^{\mathrm{d}} \mathrm{INAF}$ - Osservatorio Astrofisico di Catania (Italy);-
${ }^{\mathrm{e}} \mathrm{INAF}$ - Osservatorio Astronomico di Capodimonte (Italy);-
${ }_{\mathrm{f}}^{\mathrm{f}}$ Astronomical Institute of the Acad.of Sciences,. (Czech Republic); ${ }^{\mathrm{g}}$ Consiglio Nazionale delle Ricerche (Italy); ${ }^{\mathrm{h}}$ University of Pavia (Italy);
${ }^{i}$ U.S. Naval Research Laboratory (USA); ${ }^{1}$ INAF-IASF Milano, Italy; ${ }^{\mathrm{m}}$ Max-Plank-Institute für Sonnensystemforschung, (Germany); ${ }^{\mathrm{n}}$ INAF- IASF Roma (Italy); ${ }^{\mathrm{r}}$ Laboratoire d'Astrophysique de Marseille(France) \\ ${ }^{\mathrm{p}}$ Institut d'Astrophysique Spatiale (France); ${ }^{\mathrm{q}} \mathrm{INAF}$ - Osservatorio Astronomico di Palermo (Italy);
}

\begin{abstract}
METIS, the "Multi Element Telescope for Imaging and Spectroscopy", is a coronagraph selected by the European Space Agency to be part of the payload of the Solar Orbiter mission to be launched in 2017. The unique profile of this mission will allow 1) a close approach to the Sun (up to 0.28 A.U.) thus leading to a significant improvement in spatial resolution; 2) quasi co-rotation with the Sun, resulting in observations that nearly freeze for several days the large-scale outer corona in the plane of the sky and 3) unprecedented out-of-ecliptic view of the solar corona.

This paper describes the experiment concept and the observational tools required to achieve the science drivers of METIS. METIS will be capable of obtaining for the first time:

- $\quad$ simultaneous imaging of the full corona in polarized visible-light (590-650 nm) and narrow-band ultraviolet HI Lyman $\alpha(121.6 \mathrm{~nm})$;

- $\quad$ monochromatic imaging of the full corona in the extreme ultraviolet He II Lyman $\alpha(30.4 \mathrm{~nm})$;

- $\quad$ spectrographic observations of the HI and He II Ly $\alpha$ in corona.
\end{abstract}

These measurements will allow a complete characterization of the three most important plasma components of the corona and the solar wind, that is, electrons, hydrogen, and helium. This presentation gives an overview of the METIS imaging and spectroscopic observational capabilities to carry out such measurements.

Keywords: Solar instrumentation, Coronagraphy, UV imaging, UV Spectrography., visible-light polarimetry

Space Telescopes and Instrumentation 2012: Ultraviolet to Gamma Ray,

edited by Tadayuki Takahashi, Stephen S. Murray, Jan-Willem A. den Herder,

Proc. of SPIE Vol. 8443, 844309 - (C) 2012 SPIE · CCC code: 0277-786/12/\$18 · doi: 10.1117/12.927222

Proc. of SPIE Vol. $8443844309-1$ 


\section{INTRODUCTION}

Solar Orbiter [1] is one of the Medium-class missions selected for launch by ESA in the framework of the Cosmic Vision 2015-2025 program (with Euclid), aimed to study the Sun and the inner heliosphere, with a payload made up of scientific instrumentation specifically designed to identify the origins and causes of the solar wind, the solar energetic particles, the transient interplanetary disturbances, and the heliospheric and Sun's magnetic field.

Solar Orbiter will provide the next major step forward in the exploration of the Sun and the heliosphere after the successful ESA missions Ulysses and SOHO, as well as the NASA missions TRACE, RHESSI, STEREO and SDO, and the ISAS mission, Hinode. It will be a key element of the International Living with a Star program, focused on the space research that has the objective of understanding the processes governing the connected Sun-heliosphere system.

Solar Orbiter will be launched from the Kennedy Space Center on January 2017 (nominal launch date) and after a cruise phase lasting approximately three years it will start its 7.5 years-long nominal mission phase during which it will orbit the Sun in about six months and will achieve perihelion distances down to 0.28 Astronomical Units (AU), getting closer to the Sun than any previous spacecraft. Solar Orbiter will be in a privileged position suitable to perform unprecedented scientific observations thanks to a powerful combination of in-situ and remote sensing instrumentation. Thanks to regular gravity-assist maneuvers at Venus the orbit will be tilted bringing the spacecraft to increasingly higher latitudes, allowing a view of the Sun's polar regions from latitudes higher than $30^{\circ}$ (up to $34^{\circ}$ close to the end of the mission). Moreover, Solar Orbiter will be almost co-rotating with the Sun for a part of its orbit, providing for the first time the capability of remote-sensing solar storms and coronal eruptions building up and development over an extended period (several days) from the same viewpoint.

Solar Orbiter will perform in-situ measurements of the solar wind plasma, fields, waves, and energetic particles in a region where they are still relatively unaltered and have not had their properties modified by dynamical evolution during their propagation. Moreover, remote-sensing instrumentation will carry out simultaneous, high-resolution imaging and spectroscopic observations both in and out of the ecliptic plane, allowing connecting the in-situ measurements back to their source regions and structures.

Due to the peculiar orbit of the satellite, however, the characteristics of the environment in which it shall operate heavily affect the design of its payload, which has to withstand the harsh environment and extreme temperatures

\section{METIS SCIENCE OBJECTIVES}

The Multi Element Telescope for Imaging and Spectroscopy, METIS [2], investigation has been proposed in response to the Announcement of Opportunity (D/SCI - 23482) for submitting scientific investigations for the Solar Orbiter mission, issued by the European Space Agency (ESA) on October 18, 2007, in the frame of a joint ESA-NASA program.

The design of METIS, conceived to perform off-limb and near-Sun coronagraphy and spectrography [4], [5], is motivated by the aim of addressing the three key scientific questions: i) the origin and heating/acceleration of the solar wind streams; ii) the origin, acceleration and transport of the solar energetic particles; and iii) the transient ejection of coronal mass and its evolution in the inner heliosphere (coronal mass ejections, CME's).

The investigation aims to provide crucial tests apt to verify the hypotheses and models on the following main issues of solar coronal physics, that have been developed primarily during the SOHO era:

- Is the slow solar wind originating according to more than one physical process and which is the level of contribution of the possible different sources of slow wind to the heliospheric wind observed 'in situ'?

- How does the magnetic field topology control the outflow velocity and composition of the slow and fast solar wind? [3]

- Is the magnetic field controlling the emergence of the fast wind at the base of coronal holes?

- Do polar plumes and inter-plume regions have a role in channeling the fast wind?

- Is ion cyclotron dissipation of fast Alfvén waves the primary energy deposition process in the fast wind?

- Is the reconnection at the base of coronal holes responsible for the generation of waves and turbulence that energize the fast wind?

- Which is the nature of coronal heating in open and closed field regions?

- Which is the source of the seed particles of the Solar Energetic Particles (SEPs)? 
- Which is the role of coronal shocks driven by coronal mass ejections in energizing SEPs?

- Which are the mass and magnetic fluxes carried out from the Sun during transient events?

- How does the evolution of the coronal magnetic field, inferred from the large-scale evolution of the outer corona, trigger coronal mass ejections?

- How does the corona re-adjust after coronal mass ejections on medium-term time scales, ranging between 3 and 10 days (not yet established in the outer corona)?

- How do the quiescent streamers evolve on time scales ranging between 3 and 10 days?

The crucial tests for addressing and solving these still open issues can be achieved by combining the instrument's versatility with the uniqueness of the Solar Orbiter mission profile, that is: a close approach to the Sun thus leading to a significant improvement in spatial resolution; quasi co-rotation with the Sun, which allows to nearly freeze for several days both the on-disk inner corona and the outer corona in the plane of the sky and, thus, disentangle the evolution of coronal structures and solar rotational effects on medium-term time scales, an out-of-ecliptic view of the Sun.

\subsection{Measurements Requirements}

METIS instrument is designed to combine and extend the imaging and spectroscopic capabilities of the SOHO and STEREO coronagraphs and spectrometers in order to exploit at best the unique characteristic of the Solar Orbiter mission profile. It can simultaneously image the visible and ultraviolet emission of the solar corona and diagnose, with unprecedented temporal coverage and spatial resolution (down to about $2000 \mathrm{~km}$ ), the structure and dynamics of the full corona in the range from 1.5 to 3 (from 1.7 to 3.5 ) solar radii $\left(\mathrm{R}_{\odot}\right.$ ) from Sun center, at minimum (maximum) perihelion during the nominal mission, a region which is crucial in linking the solar atmosphere phenomena to their evolution in the inner heliosphere. In addition, it can combine both coronagraphy and spectrography to observe the EUV spectral emission of the two most abundant solar elements in the geo-effective coronal region from 1.5 to $3 \mathrm{R}_{\odot}$ from Sun center, at the closest approach (cfr. Figure 1). METIS will be capable of obtaining for the first time [2], [4], [5]:

- $\quad$ simultaneous imaging of the full corona in polarized broad-band (590-650 nm) visible-light (VL) and narrow-band ultraviolet (UV) HI Lyman $\alpha(121.6 \mathrm{~nm})$;

- monochromatic imaging of the full corona in the extreme ultraviolet (EUV) He II Lyman $\alpha(30.4 \mathrm{~nm})$;

- $\quad$ spectroscopic observations of HI and He II Lyman $\alpha$ in corona.

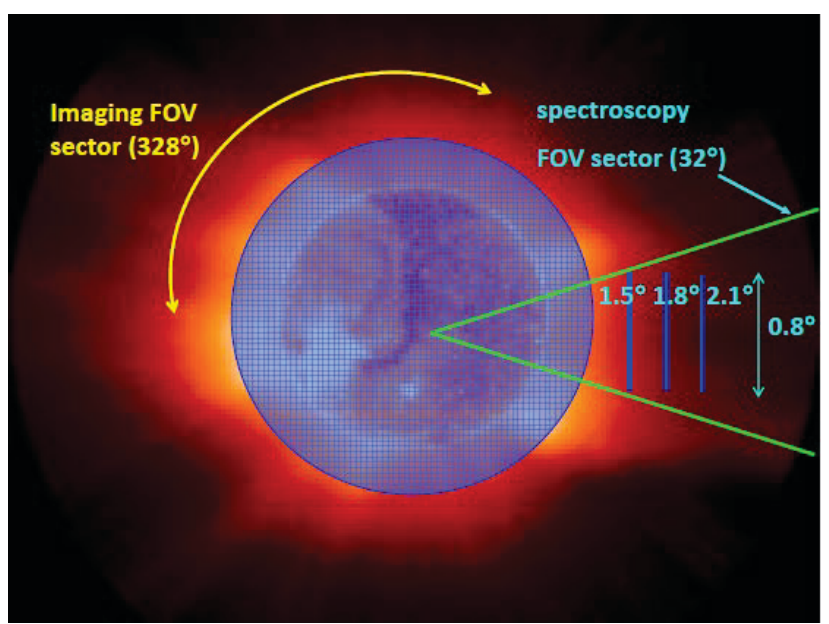

Figure 1 Imaging and spectrographic multi-slits field-of-view (FOV) at $0.28 \mathrm{AU}$ for the EUV/UV spectroscopic path. The FOV sector for spectroscopy is about $32^{\circ}$. The remaining FOV is used for imaging in the three wavelength bands: $30.4 \mathrm{~nm}, 121.6 \mathrm{~nm}$, visible-light.
These measurements will allow a complete characterization of the three most important plasma components of the corona and the solar wind (electrons, protons, helium). Table 1 shows the METIS Science and Instrumentation Traceability Matrix

The instrument has been designed following a highly innovative approach, which takes advantage of the multiwavelength capabilities of a telescope which uses optics coated with multilayers highly reflective in the visiblelight band and in the EUV/UV band, as well.

The coronagraph is based on a novel externally occulted design, in which light enters through a circular inverted external occulter (IEO) located at the outside panel of the $\mathrm{S} / \mathrm{C}$ heat shield [6]. The IEO is supported by a suitable truss, which protrudes from the $\mathrm{S} / \mathrm{C}$ instrument bay inside the heat shield. Three different coronal light wavelengths can be selected by a filter mechanism: either visible, collected by a visible detector after being passed through a polarizer, and UV (HI $121.6 \mathrm{~nm}$ ) or EUV (HeII $30.4 \mathrm{~nm}$ ) lines collected by a EUV/UV detector. 


\begin{tabular}{|c|c|c|c|c|c|c|}
\hline \multirow{2}{*}{$\begin{array}{l}\text { Science } \\
\text { Objective }\end{array}$} & \multirow{2}{*}{$\begin{array}{l}\text { Science } \\
\text { Question }\end{array}$} & \multirow{2}{*}{$\begin{array}{l}\text { Measurement } \\
\text { Requirement }\end{array}$} & \multicolumn{2}{|c|}{ Resolution } & \multirow{2}{*}{$\begin{array}{l}\text { Signal to- } \\
\text { Noise Ratio }\end{array}$} & \multirow{2}{*}{ Field of View } \\
\hline & & & Temporal & Spatial & & \\
\hline \multirow{5}{*}{$\begin{array}{l}\text { A) Origins } \\
\text { and } \\
\text { acceleration } \\
\text { of solar } \\
\text { wind } \\
\text { streams }\end{array}$} & \multirow{2}{*}{$\begin{array}{l}\text { A1) What is } \\
\text { the } \\
\text { mechanism of } \\
\text { energy } \\
\text { deposition in } \\
\text { the fast wind? }\end{array}$} & $\begin{array}{l}\text { (Imaging) Global maps of } \\
\text { outflow velocities of } \mathrm{H}^{0}, \mathrm{He}^{+}\end{array}$ & $\begin{array}{l}\text { VL } 10 \mathrm{~min} \\
\text { UV } 15 \mathrm{~min} \\
\text { EUV } 240 \mathrm{~min}\end{array}$ & $40 "$ & $\begin{array}{l}\text { VL: } 29-515 \\
\text { UV: } 6-61 \\
\text { EUV: } 10-95\end{array}$ & $\begin{array}{l}1.5^{\circ}-3^{\circ} \\
\text { annular; off-limb } \\
\text { corona }\end{array}$ \\
\hline & & $\begin{array}{l}\text { (Spectrography) Intensities } \\
\text { and profiles of HI and HeII } \\
\text { Ly- } \alpha \text { for line-of-sight speeds }\end{array}$ & $\begin{array}{l}\text { UV } 120 \mathrm{~min} \\
\text { EUV } 600 \mathrm{~min}\end{array}$ & $45^{\prime \prime}$ & $\begin{array}{l}\text { UV 26-37 } \\
\text { EUV 6-8 }\end{array}$ & $\begin{array}{l}1.5^{\circ}-2.1^{\circ} 32^{\circ} \text { sector } \\
\text { off-limb corona }\end{array}$ \\
\hline & $\begin{array}{l}\text { A2) What is } \\
\text { the origin of } \\
\text { solar wind } \\
\text { turbulence? }\end{array}$ & $\begin{array}{l}\text { (Imaging) Measure time } \\
\text { series of velocity and } \\
\text { brightness of solar wind; } \\
\text { best during corotation }\end{array}$ & $\begin{array}{l}\text { VL } 0.5 \mathrm{~min} \\
\text { UV } 0.5 \mathrm{~min}\end{array}$ & $40 "$ & $\begin{array}{l}\text { VL: 6-115 } \\
\text { UV } \\
\text { Stream: 6-11 } \\
\text { Poles: } 5 \\
\end{array}$ & $\begin{array}{l}1.5^{\circ}-3^{\circ} \\
\text { annular, off-limb } \\
\text { corona }\end{array}$ \\
\hline & $\begin{array}{l}\text { A3) How does } \\
\text { the magnetic } \\
\text { topology } \\
\text { control the } \\
\text { wind speed? }\end{array}$ & $\begin{array}{c}\text { (Imaging) Global maps of } \\
\text { outflow velocities of } \mathrm{H}^{0} \text { and } \\
\mathrm{He}^{+} \text {for absolute abundance; } \\
\text { best during corotation }\end{array}$ & $\begin{array}{l}\text { VL } 2 \text { min } \\
\text { UV } 10 \mathrm{~min} \\
\text { EUV } 120 \mathrm{~min}\end{array}$ & $40^{\prime \prime}$ & $\begin{array}{l}\text { VL } 13-230 \\
\text { UV } 5-50 \\
\text { EUV } 7-66\end{array}$ & $\begin{array}{l}1.5^{\circ}-3^{\circ} \\
\text { annular; off-limb } \\
\text { corona }\end{array}$ \\
\hline & $\begin{array}{l}\text { A4) What are } \\
\text { the sources of } \\
\text { the slow solar } \\
\text { wind? }\end{array}$ & $\begin{array}{l}\text { (Imaging) Maps of outflow } \\
\text { velocities, and absolute } \\
\text { densities of } \mathrm{H}^{0} \text { and } \mathrm{He}^{+} \\
\text {best during corotation }\end{array}$ & $\begin{array}{l}\text { VL } 2 \text { min } \\
\text { UV } 10 \mathrm{~min} \\
\text { EUV } 120 \mathrm{~min}\end{array}$ & $40^{\prime \prime}$ & $\begin{array}{l}\text { VL } 13-230 \\
\text { UV 5-50 } \\
\text { EUV 7-67 }\end{array}$ & $\begin{array}{l}1.5^{\circ}-3^{\circ} \\
\text { annular; off-limb } \\
\text { corona }\end{array}$ \\
\hline \multirow{3}{*}{$\begin{array}{l}\text { B) Sources, } \\
\text { acceleration } \\
\text { mechanism } \\
\text { and transport } \\
\text { processes of } \\
\text { Solar } \\
\text { Energetic } \\
\text { Particles } \\
\text { (SEPs) }\end{array}$} & \multirow{2}{*}{$\begin{array}{l}\text { B1) How are } \\
\text { SEPs } \\
\text { produced by } \\
\text { CMEs and } \\
\text { their } \\
\text { associated } \\
\text { shocks? }\end{array}$} & $\begin{array}{l}\text { (Imaging) Global maps of } \mathrm{e}^{-} \\
\text {density in pre-CME coronal } \\
\text { ambient, multi-wavelength } \\
\text { UV intensities for deriving } \\
\text { ionization states in shocks }\end{array}$ & $\begin{array}{l}\text { VL } 2 \text { min } \\
\text { UV } 4 \text { min } \\
\text { EUV } 32 \text { min }\end{array}$ & $20 "$ & $\begin{array}{c}\text { VL } 13-230 \\
\text { UV 3-31 } \\
\text { EUV } 3.6-34\end{array}$ & $\begin{array}{l}1.5^{\circ}-3^{\circ} \\
\text { annular, off-limb } \\
\text { corona }\end{array}$ \\
\hline & & $\begin{array}{l}\text { (Spectrography) HI Ly- } \alpha \\
\text { line profile; best } \leq 0.3 \mathrm{AU}\end{array}$ & $\begin{array}{l}\text { UV } 10 \mathrm{~min} \\
\text { EUV } 60 \mathrm{~min}\end{array}$ & $45^{\prime \prime}$ & $\begin{array}{l}\text { UV } 7.5-35 \\
\text { EUV } 15 \\
\end{array}$ & $\begin{array}{c}1.5^{\circ}-2.1^{\circ}-32^{\circ} \text { sector } \\
\text { off-limb corona }\end{array}$ \\
\hline & $\begin{array}{l}\text { B2) How are } \\
\text { SEPs } \\
\text { accelerated in } \\
\text { flares? }\end{array}$ & $\begin{array}{l}\text { Detection and timing of } \\
\text { CMEs to help distinguishing } \\
\text { flare-accelerated SEPs from } \\
\text { those associated with CMEs. }\end{array}$ & $\begin{array}{l}\text { VL } 2 \text { min } \\
\text { UV } 4 \mathrm{~min} \\
\text { EUV } 32 \mathrm{~min}\end{array}$ & $40 "$ & $\begin{array}{c}\text { VL 13-23) } \\
\text { UV 3-31 } \\
\text { EUV 3.6-34 }\end{array}$ & $\begin{array}{l}1.5^{\circ}-3^{\circ} \\
\text { annular, off-limb } \\
\text { corona }\end{array}$ \\
\hline \multirow{3}{*}{$\begin{array}{l}\text { C) Origin } \\
\text { and early } \\
\text { propagation } \\
\text { of coronal } \\
\text { mass } \\
\text { ejections } \\
\text { (CMEs) }\end{array}$} & $\begin{array}{l}\text { C1) What is } \\
\text { the mech. } \\
\text { driving the } \\
\text { eruption of } \\
\text { CMEs? }\end{array}$ & $\begin{array}{l}\text { (Imaging) UV and visible- } \\
\text { light imaging of CME pre- } \\
\text { eruption, eruption and } \\
\text { reconfiguration of ambient } \\
\text { corona; best out of ecliptic }\end{array}$ & $\begin{array}{l}\text { VL } 2 \text { min } \\
\text { UV } 4 \mathrm{~min}\end{array}$ & $20 "$ & $\begin{array}{l}\text { VL } 13-230 \\
\text { UV 3-31 }\end{array}$ & $\begin{array}{l}1.5^{\circ}-3^{\circ} \\
\text { annular; off-limb } \\
\text { corona }\end{array}$ \\
\hline & $\begin{array}{l}\text { C2) What is } \\
\text { the evolution } \\
\text { of cool } \\
\text { plasma in } \\
\text { CMEs? }\end{array}$ & $\begin{array}{l}\text { (Spectrography) Intensities } \\
\text { and profiles of HI and HeII } \\
\text { Ly- } \alpha \text { lines and possibly } \\
\text { nearby lines of cool ions } \\
\text { (e.g., SiIII } 120.6 \mathrm{~nm} \text { ) }\end{array}$ & $\begin{array}{l}\text { UV } 10 \mathrm{~min} \\
\text { EUV } 40 \mathrm{~min} \\
\text { streamers }\end{array}$ & $45^{\prime \prime}$ & $\begin{array}{l}\text { UV 32-35 } \\
\text { EUV 11-12 } \\
\text { streamers }\end{array}$ & $\begin{array}{l}1.5^{\circ}-2.1^{\circ} \\
32^{\circ} \text { sector off-limb } \\
\text { corona }\end{array}$ \\
\hline & $\begin{array}{l}\text { C3) How does } \\
\text { the global } \\
\text { corona } \\
\text { evolve? }\end{array}$ & $\begin{array}{l}\text { Follow evolution of CMEs } \\
\text { with UV and visible-light } \\
\text { imaging from the coronal } \\
\text { base ( } 1.5 \text { Ro at } 0.28 \mathrm{AU})\end{array}$ & $\begin{array}{l}\text { VL } 10 \text { min } \\
\text { UV } 5 \text { min }\end{array}$ & $40 "$ & $\begin{array}{l}\text { VL } 29-515 \\
\text { UV } 3.4-35\end{array}$ & $\begin{array}{l}1.5^{\circ}-3^{\circ} \\
\text { annular; off-limb } \\
\text { corona }\end{array}$ \\
\hline
\end{tabular}

Table 1 Science and Instrumentation Traceability Matrix. 


\subsection{Coronal UV and EUV Radiances}

The signal-to-noise ratios (SNR) in the measurements required to achieve the science goals, and summarized in the Traceability Matrix of Table 1, are obtained by optimizing the instrument response against the coronal signal. Figure 2 shows the intensities of the H I $121.6 \mathrm{~nm}$ and He II $30.4 \mathrm{~nm}$ lines at different heliocentric distances in the extended solar corona, for representative coronal structures, such as streamers and coronal holes. The intensity values are obtained from $\mathrm{SOHO} / \mathrm{UVCS}$ observations, for the HI Ly- $\alpha$ line (right), and from numerical simulations for the HeII Ly- $\alpha$ line, assuming models for typical coronal structures (left) [9], [10], [11], [12]. As for the radiance of the HeII, $30.4 \mathrm{~nm}$ line, the calculations refer only to the Sun at its minimum of activity. The variability in the HI measurements and in the models adopted for the HeII calculations are reflected in shaded areas of the intensity profiles plotted in Figure 2

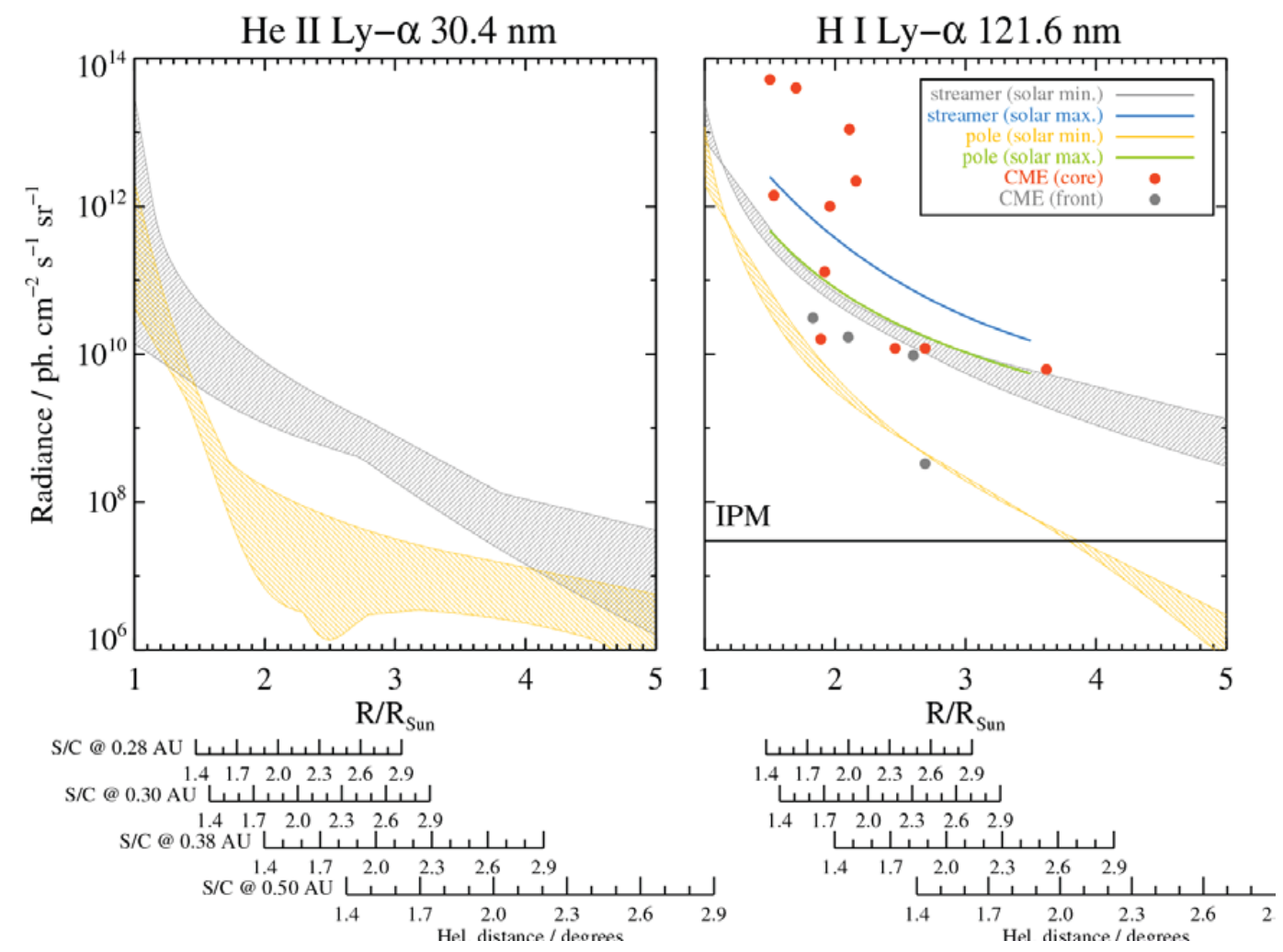

Figure 2 Measured HI $121.6 \mathrm{~nm}$ (right) and estimated He II $30.4 \mathrm{~nm}$ (left) coronal radiances for different coronal structures.

The heliocentric distances are converted to angular distances for several spacecraft-Sun distances in the bottom axes.

\section{METIS EXPERIMENT OVERVIEW}

METIS, the Multi Element Telescope for Imaging and Spectroscopy, is one of the remote-sensing instruments of Solar Orbiter consisting in an innovative coronagraph for the study and overall characterization of the solar corona [4], [5], [6]. METIS is an inverted-occultation coronagraph that by a combination of multilayer mirror coatings and spectral bandpass filters, will image the solar corona in three different wavelengths: in visible light, between 590 and $650 \mathrm{~nm}$, and in the two Lyman- $\alpha$ lines of neutral hydrogen (HI at $121.6 \mathrm{~nm}$ ) and of singly-ionized helium (HeII at $30.4 \mathrm{~nm}$ ) (Figure 3).

The visible-light channel also includes a polarimeter to observe the linearly polarized brightness (pB) of the K corona. In addition, METIS will have the capability of collecting spectra of the HI and HeII Lyman lines simultaneously at three different heights (accomplished by a multiple slit) in a $32^{\circ}$ angular sector of the corona (Figure 1). These measurements will allow a complete characterization of the three most important plasma components of the corona and the solar wind: electrons, protons, and helium. 


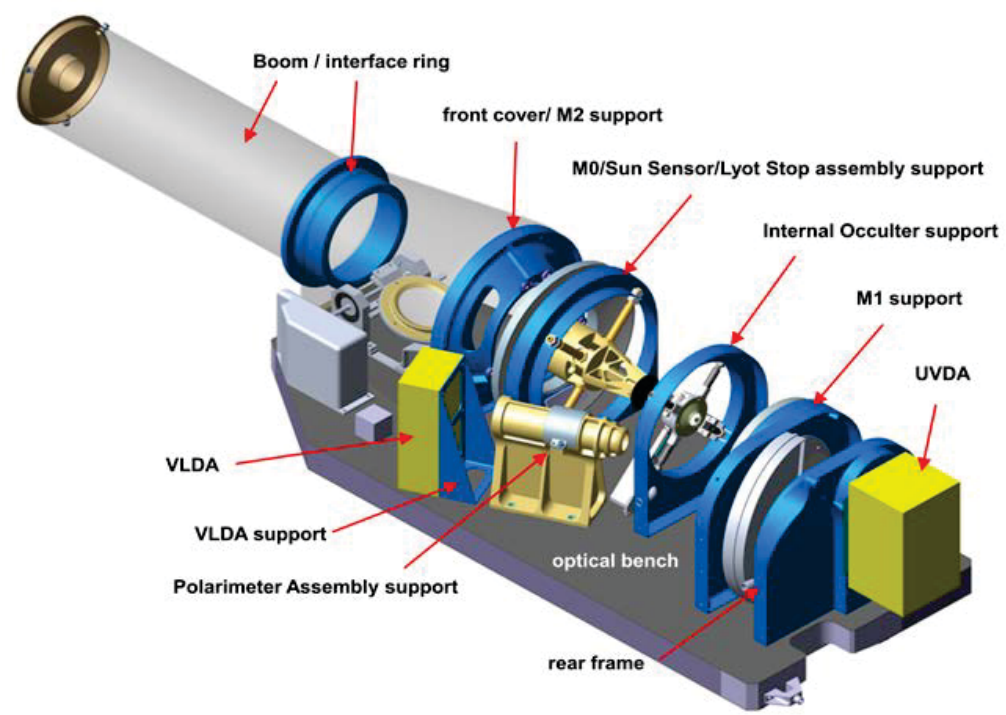

Figure 3 METIS opto-mechanical layout showing the main telescope elements [courtesy of Thales Alenia Space Italia].

\begin{tabular}{|c|c|}
\hline \multicolumn{2}{|c|}{ METIS Instrument Performances } \\
\hline \multicolumn{2}{|l|}{ CORONAL IMAGING } \\
\hline Avg. Instrumental Stray Light $\left(\mathrm{B}_{\text {cor }} / \mathrm{B}_{\odot}\right)$ & $\begin{array}{l}\mathrm{VL}<10^{-9} \\
\text { UV/EUV }<10^{-7}\end{array}$ \\
\hline Wavelength range: & $\begin{array}{l}\text { VL: } 590-650 \mathrm{~nm} ; \\
\text { UV: } 121.6 \pm 10 \mathrm{~nm} \\
\text { EUV: } 30.4 \pm 2 \mathrm{~nm}\end{array}$ \\
\hline Spatial resolution & $20 \operatorname{arcsec}$ \\
\hline Field of view & $1.5^{\circ}-2.9^{\circ}$ annular, off-limb corona \\
\hline \multicolumn{2}{|l|}{ CORONAL SPECTROGRAPHY } \\
\hline Wavelength range: & $\begin{array}{l}\text { UV: } 121.6 \pm 0.9 \mathrm{~nm} \\
\text { EUV: } 30.4 \pm 0.22 \mathrm{~nm}\end{array}$ \\
\hline Spectral resolution & $\begin{array}{l}\text { UV: } 0.072 \mathrm{~nm} \\
\text { EUV: } 0.018 \mathrm{~nm}\end{array}$ \\
\hline Spatial resolution & $45 \operatorname{arcsec}$ \\
\hline Field of view & $\begin{array}{l}\text { Slit radial positions: } 1.5^{\circ}, 1.8^{\circ}, 2.1^{\circ} \\
\text { Slit extension: } 0.8^{\circ}\end{array}$ \\
\hline \multicolumn{2}{|l|}{ GENERAL } \\
\hline Telemetry rate & $10 \mathrm{kbit} / \mathrm{s}$ \\
\hline Data volume (compression up to 10 ) & $26 \mathrm{~Gb} /$ orbit \\
\hline
\end{tabular}

Table 2 METIS instrument performances.

Proc. of SPIE Vol. $8443844309-6$ 


\subsection{Instrument Performances}

METIS is designed to address the science questions summarized in the Traceability Matrix (Table 1) by combining the imaging and spectroscopic capabilities of coronagraphs and spectrometers. The coronagraph can simultaneously image the visible-light and ultraviolet emissions of the solar corona and diagnose, with unprecedented temporal coverage and spatial resolution the structure and dynamics of the full corona in the field-of-view (FOV) range from $1.5^{\circ}$ to $3^{\circ}$, corresponding to 1.5 to $3 \mathrm{R}_{\odot}$, at minimum perihelion $(0.28 \mathrm{AU})$, and 2.6 to $5.5 \mathrm{R}_{\odot}$, at $0.5 \mathrm{AU}$. Table 2 summarizes the instrument performances. METIS is an externally occulted coronagraph. The occultation scheme is based on an inverted external-occulter (IEO). The IEO consists of a single, small $(\varnothing 40 \mathrm{~mm})$ circular aperture. A small $(\varnothing 71 \mathrm{~mm}) \mathrm{spherical}$ mirror (M0) rejects back the disk-light through the IEO up to $1.1^{\circ}$ (i.e., $1.17 \mathrm{R}_{\odot}$ at $0.28 \mathrm{AU}$ ) [6], [7], [8].

\section{INSTRUMENT OPTICAL DESIGN}

The inverted external occulter (IEO) consists of a circular aperture on a disk kept by a cylindrical boom at $500 \mathrm{~mm}$ in front of the telescope. The disk-light through the IOE is rejected back by a spherical heat-rejection mirror (M0). The coronal light, on the other hand, is collected by an on-axis Gregorian telescope. The suppression of the diffracted light off the edges of the IOE and M0 is achieved, respectively, with an internal occulter (IO) and a Lyot trap (LS). Ref. [7] gives a detailed description of the METIS optical design. Figure 4 shows a schematic layout of the inverted-occultation coronagraph.

METIS includes 4 optical paths:

1. linearly polarized visible-light $(590-650 \mathrm{~nm})$

2. narrow-band ultraviolet HI Lyman $\alpha(121.6 \mathrm{~nm})$

3. narrow-band extreme ultraviolet He II Ly $\alpha(30.4 \mathrm{~nm})$.

4. spectrographic observations of H I Lyman $\alpha$ and He II Lyman $\alpha$ in corona.

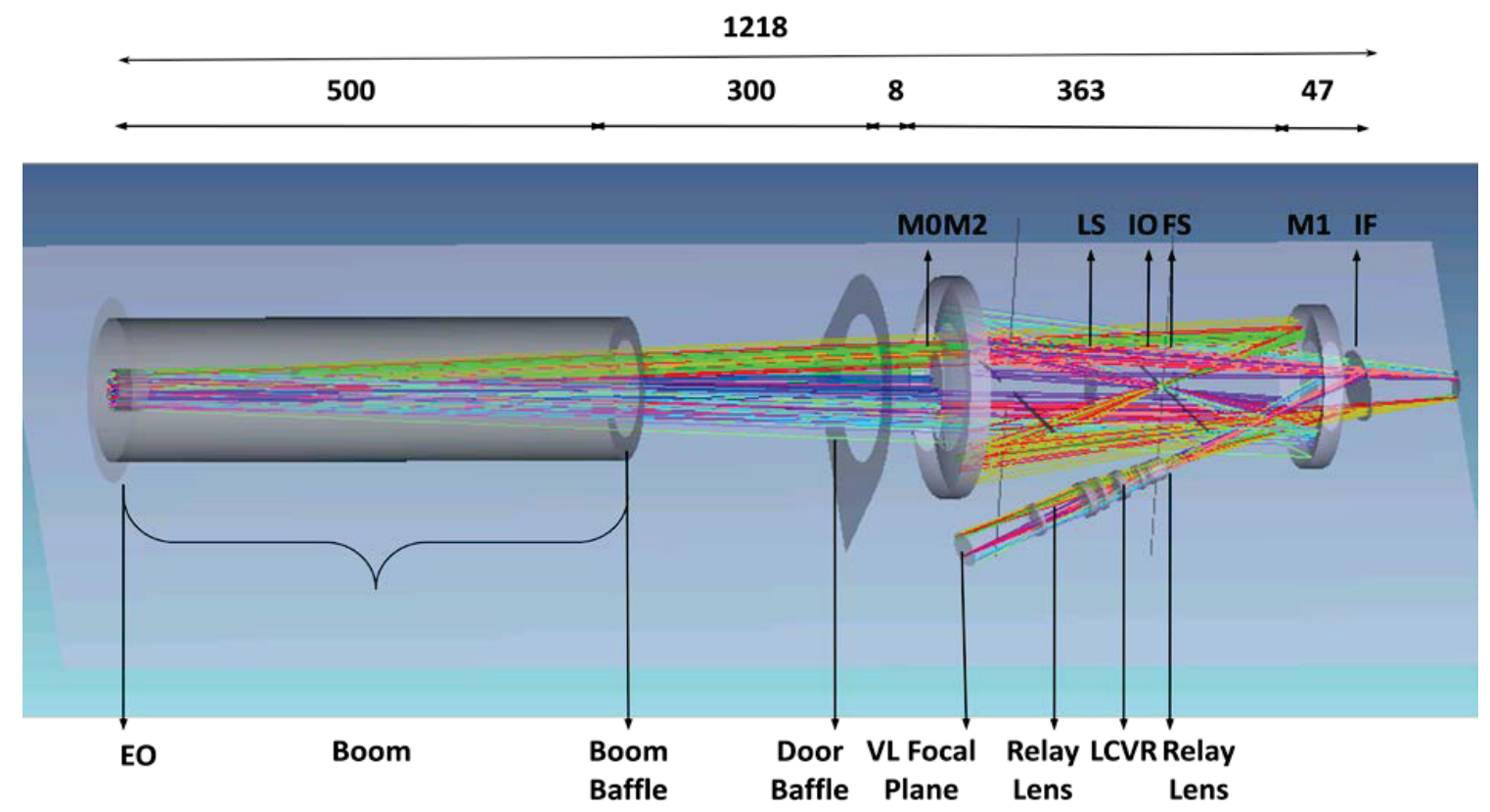

Figure 4: Optical layout of the Visible-Light and UV/EUV paths in the inverted-occultation coronagraph. 


\subsection{UV/EUV Imaging Paths}

The ultraviolet (UV) and visible-light (VL) paths are split by an UV interference filter at $12^{\circ}$ (cfr. Figure 4). The UVcapped multilayer (ML) coatings in the primary (M1) and secondary (M2) telescope mirrors are optimized for narrow bandpass reflectivity at $30.4 \mathrm{~nm}$. The ML cap-layer has good reflectivity also in the UV (122 nm) and visible-light (590$650 \mathrm{~nm}$ ) [13]. In the extreme UV (EUV) path, the longer wavelengths are blocked by an Al filter. The UV filter selects the $122 \mathrm{~nm}$ UV band and reflects the VL band. Ref. [7] describes in detail the optical performances of the METIS UV/EUV Imaging Paths.

\subsection{Visible-light Path and Polarimeter}

The VL Path includes a polarimeter consisting of a polarimetric optical system (POS) and a relay-optics system (ROS). The ROS collimates, through the POS, the light from the image formed by the telescope on the intermediate VL focal plan. Then the ROS re-focuses the image on the VL detector, with a 1:1.2 magnification ratio to match the telescope plate scale with the APS pixel size. The POS electro-optically modulates the intensity of the linearly polarized brightness (pB) of the visible-light K-corona. The POS is comprised of polarization optics in "Senarmont configuration":bandpass filter (590-650 nm); fixed quarter-wave retarder; polarization modulation package (PMP) with a LCVR cell (Liquid Crystal Variable Retarder); linear polarizer [14], [15]. A detailed description of the VL Path is given in Ref. [16].

\subsection{EUV/UV Spectrographic Path}

The EUV/UV spectrographic path in METIS consists of a sector of the telescope primary mirror (M1) that is used for feeding a multi-slit spectrograph. In the spectrograph, the grating replaces a sector of the secondary mirror (M2). The grating diffracts the spectrum on the portion of the detector that is not used for coronal EUV/UV imaging.. The grating is a spherical variable-line-spaced (SVLS) one with a ruling frequency of 1800 lines $/ \mathrm{mm}$. The SVLS grating diffracts the $30.4-\mathrm{nm}$ radiation at $4^{\text {th }}$ order and the $121.6-\mathrm{nm}$ radiation at $1^{\text {st }}$ order on the same location on the focal plane. The multislit input section selects a number of angular field-of-views (FOVs): $1.5^{\circ}, 1.8^{\circ}$ and $2.1^{\circ}$ (Figure 1). The spectral separation between the slits is $0.44 \mathrm{~nm}$ at $30.4 \mathrm{~nm}$, and $1.74 \mathrm{~nm}$ at $121.6 \mathrm{~nm}$. This minimizes the overlap between the wings of spectral lines profiles in adjacent slits. ). Ref. [7] describes in detail the optical layout of the METIS Spectrographic Path with the SVLS grating.

\section{DETECTORS ASSEMBLIES}

The detectors assemblies turn into electronic signals the coronal light collected by the METIS telescope. The multilayercoated mirrors of the telescope enable the simultaneous operation of both the VL detector (VLD) and the EUV/UV detector (UVD), in visible light and HI Ly- $\alpha$, respectively. When the HeII Ly- $\alpha$ channel is selected only the UVD detector is used.

The VLD assembly hosts a Teledyne $2 \mathrm{k} \times 2 \mathrm{k}, 18 \mu \mathrm{m}$ pixel size, CMOS Active Pixel Sensor (APS), the HyViSi model coupled with the H2RG (HAWAII 2RG) Read Out Integrated Circuit (ROIC) multiplexer [17]. This APS is managed directly by the Teledyne SIDECAR, an ASIC integrating a microcontroller with program and data memory able to operate the APS, including bias and clocks generation [18]. The ASIC is connected with a small board providing a SpaceWire (SpW) interface to the MPPU for data transfer, telemetry (TM) and telecommand (TC) purposes.

The UVD channel assembly hosts an Intensified Active Pixel Sensor (IAPS) in a $1 \mathrm{k} \times 1 \mathrm{k}$ format, $15-\mu \mathrm{m}$ pixel size. that can be operated in photon counting regime. Observing in the EUV requires a windowless UVD, while radiation hardness requirements and readout flexibility are satisfied by the characteristics of the space qualified Cypress STAR1000 CMOS active pixel sensor.

The IAPS is based on a microchannel plate (MCP) intensifier with a phosphor screen output, optically coupled via a 2:1 de-magnifying fiber optic taper to the CMOS sensor. A photocathode deposited on the entrance MCP face converts the incoming photons in primary photoelectrons, which are then multiplied by the MCP and finally converted into optical photons by means of the phosphor screen. At the phosphor output, the APS detects these optical photons and converts 
them into electrons. The voltage level resulting from the current to voltage amplification and conversion is digitized with a 14-bits resolution $\mathrm{ADC}$ at a frame rate up-to $12 \mathrm{MHz}$ [19] .

The UVD digital processing electronics is interfaced to the METIS Processing \& Power Unit (MPPU) thanks to a small electronics board called DCB (Detector Control Board) hosting a Spacewire (SpW) link and the interface to the voltage lines needed to feed the whole assembly [20]. The presence of the DCB also provides a suitable way to test the detector systems independently from the MPPU. No microcontroller or microprocessors are foreseen on board the DCB as baseline. The DCB shall manage processing functions only by hardware, exploiting a suitable FPGA.

An internal ion pump is used as Ground Support Equipment (GSE) in order to evacuate the UVD assembly. This connected to a Service Unit hosting the High Voltage Power Supply (HVPS) for the MCP, the ion pump driver and the electrical driver for the UVD External Door Windows Mechanism (EDWM), to be open in vacuum.

\section{INSTRUMENT RESPONSE ESTIMATE}

\subsection{Effective areas}

The total throughputs of the METIS 4-channel instrument are derived from the component level efficiencies (Table 3).

\begin{tabular}{|l|c|c|c|c|}
\hline \multicolumn{1}{|c|}{ Instrument subsystem } & $\mathbf{3 0 . 4} \mathbf{~ n m}$ & $\mathbf{1 2 1 . 6} \mathbf{~ n m}$ & $\mathbf{5 9 0}-\mathbf{6 5 0} \mathbf{~ n m}$ & Reference \\
\hline \hline Filters transmission/reflectivity & 0.3 & 0.2 & 0.80 & Luxel Corp \& Acton Corp. \\
\cline { 1 - 4 } ML reflectivity (on M1, M2 \& grating) & 0.2 & 0.34 & 0.4 & [13] \\
\hline Grating diffraction efficiency. & 0.1 & 0.5 & N/A & Bach Research Corp. \\
\hline Polarimeter & & & 0.3 & Meadowlark Optics \\
\hline Detector Quantum Efficiency (KBr) & 0.3 & 0.17 & 0.9 & [10], [17]. [21] \\
\hline Total throughput for imaging & $3.6 \mathrm{e}-3$ & $6.9 \mathrm{e}-3$ & $3.5 \mathrm{e}-2$ & \\
\cline { 1 - 3 } Total through. for spectrography & $3.6 \mathrm{e}-4$ & $3.5 \mathrm{e}-3$ & & \\
\cline { 1 - 3 } & & &
\end{tabular}

Table 3 Estimated efficiencies of the instrument subsystems.

The effectives areas of the four METIS channels are obtained from the instrument vignetting function applied to the geometrical area of the entrance aperture $(\varnothing 40 \mathrm{~mm})$, multiplied by the instrument throughputs estimates (cfr. Table 3 ). Table 4 gives the numerical values of the effective areas of the VL path and of the EUV/UV imaging and spectrographic paths as a function of FOV

\begin{tabular}{|c|c|c|c|c|c|c|c|}
\hline \multirow{3}{*}{$\begin{array}{c}\text { Field of View } \\
{\left[{ }^{\circ}\right]}\end{array}$} & \multirow{3}{*}{$\begin{array}{c}\text { Vignetting } \\
\text { Fraction }\end{array}$} & \multirow{3}{*}{$\begin{array}{c}\text { Geometrical } \\
\text { Area }\left[\mathrm{cm}^{2}\right]\end{array}$} & \multicolumn{5}{|c|}{ Effective Areas $\left[\mathrm{cm}^{2}\right]$} \\
\hline & & & \multicolumn{2}{|c|}{$30.4 \mathrm{~nm}$} & \multicolumn{2}{|c|}{$121.6 \mathrm{~nm}$. } & \multirow{2}{*}{$590-650 \mathrm{~nm}$} \\
\hline & & & Imaging & Spectr. & Imaging & Spectr. & \\
\hline 1.50 & 0.036074 & 0.453 & $1.63 \mathrm{E}-03$ & $1.63 \mathrm{E}-04$ & $3.14 \mathrm{E}-03$ & $1.57 \mathrm{E}-03$ & $1.57 \mathrm{E}-02$ \\
\hline 1.80 & 0.131039 & 1.647 & $5.93 \mathrm{E}-03$ & $5.93 \mathrm{E}-04$ & $1.14 \mathrm{E}-02$ & $5.71 \mathrm{E}-03$ & $5.69 \mathrm{E}-02$ \\
\hline 2.10 & 0.244232 & 3.069 & $1.10 \mathrm{E}-02$ & $1.10 \mathrm{E}-03$ & $2.13 \mathrm{E}-02$ & $1.06 \mathrm{E}-02$ & $1.06 \mathrm{E}-01$ \\
\hline 2.40 & 0.362141 & 4.551 & $1.64 \mathrm{E}-02$ & & $3.16 \mathrm{E}-02$ & & $1.57 \mathrm{E}-01$ \\
\hline 2.70 & 0.481198 & 6.047 & $2.18 \mathrm{E}-02$ & & 4.19E-02 & & $2.09 \mathrm{E}-01$ \\
\hline 3.00 & 0.592734 & 7.449 & $2.68 \mathrm{E}-02$ & & $5.17 \mathrm{E}-02$ & & $1.91 \mathrm{E}-01$ \\
\hline
\end{tabular}

Table 4 Estimated effective areas of the VL path and EUV/UV imaging and spectrography paths as a function of FOV.

Figure 5 shows the effective areas for the three imaging paths as a function of field-of-view.. 


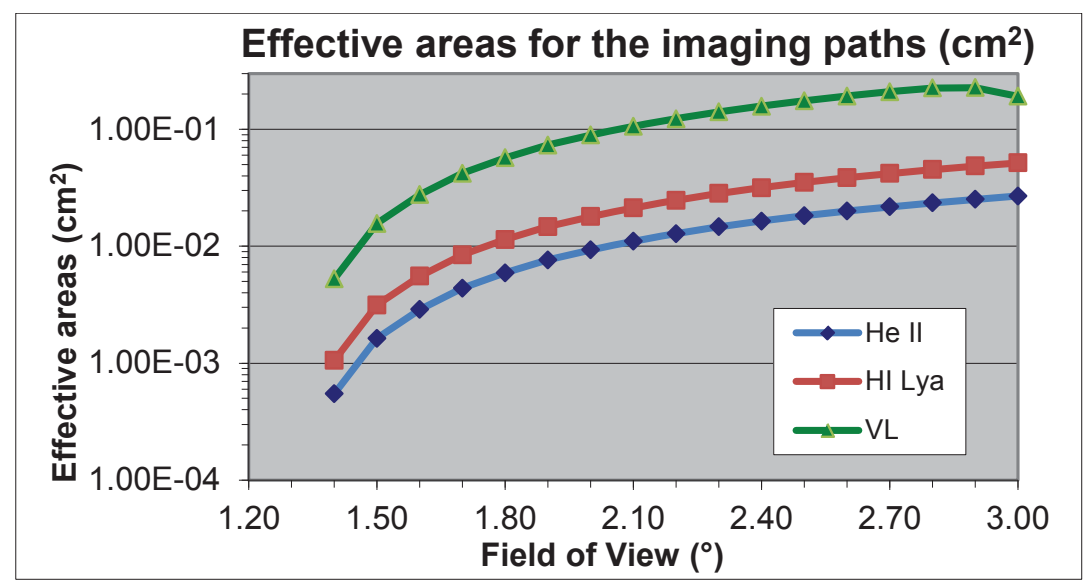

Figure 5 Estimated effective areas of the VL, EUV and UV imaging paths as a function of field-of-view.

\subsection{Expected countrates}

In order to verify that the overall performances of the METIS instrument meet the science requirements as defined in the Traceability Matrix (cfr. Table 1), the expected countrates (i.e., CR: detected-photon/s/pixel) have been estimated from the measured and calculated coronal radiances $\left(I_{c}\right.$, photons $/ \mathrm{s} / \mathrm{cm}^{2} / \mathrm{sr}$ ) shown in Figure 2, combined with the effective areas $\left(\eta, \mathrm{cm}^{2}\right)$ in Table 4:

$$
\boldsymbol{C R}\left[\text { detected-photon } / \text { s } / \text { pixel] }=\boldsymbol{I}_{c}\left[\text { photons } / \mathrm{s} / \mathrm{cm}^{2} / \mathrm{sr}\right] \times \eta\left[\mathrm{cm}^{2}\right] \times \Omega[\mathrm{sr} / \text { pixel], }\right.
$$

where, the instrument spatial plate scale is given by: $\boldsymbol{\Omega}=(10 \mathrm{arcsec})^{2} /$ pixel $=2.42 \mathrm{e}-9$ (sr/pixel) (cfr. Table 2).

The expected imaging countrates are given in Table 5 (at $0.28 \mathrm{AU}$ ) and Table 6 (at $0.5 \mathrm{AU})$.

Streamer

\begin{tabular}{|c|c|c|c|c|}
\hline FOV ${ }^{\circ}{ }^{\circ}$ & $\mathrm{R}_{\odot}$ & $30.4 \mathrm{~nm}$ & $121.6 \mathrm{~nm}$ & $\begin{array}{c}590-650 \mathrm{~nm} \\
\text { one exp of } \mathrm{pB}\end{array}$ \\
\hline 1.50 & 1.58 & $1.33 \mathrm{E}-01$ & $1.54 \mathrm{E}+00$ & $4.38 \mathrm{E}+02$ \\
\hline 1.80 & 1.89 & $1.56 \mathrm{E}-01$ & $1.83 \mathrm{E}+00$ & $4.43 \mathrm{E}+02$ \\
\hline 2.10 & 2.21 & $1.21 \mathrm{E}-01$ & $1.48 \mathrm{E}+00$ & $2.69 \mathrm{E}+02$ \\
\hline 2.40 & 2.52 & $8.64 \mathrm{E}-02$ & $1.10 \mathrm{E}+00$ & $1.56 \mathrm{E}+02$ \\
\hline 2.70 & 2.84 & $5.90 \mathrm{E}-02$ & $7.70 \mathrm{E}-01$ & $1.01 \mathrm{E}+02$ \\
\hline 3.00 & 3.16 & $3.63 \mathrm{E}-02$ & $5.19 \mathrm{E}-01$ & $3.86 \mathrm{E}+01$ \\
\hline
\end{tabular}

\section{Coronal Hole}

\begin{tabular}{|c|c|c|}
\hline $30.4 \mathrm{~nm}$ & $121.6 \mathrm{~nm}$ & $\begin{array}{c}590-650 \mathrm{~nm} \\
\text { one exp of } \mathrm{pB}\end{array}$ \\
\hline $5.13 \mathrm{E}-03$ & $1.68 \mathrm{E}-01$ & $3.41 \mathrm{E}+01$ \\
\hline $3.00 \mathrm{E}-03$ & $1.30 \mathrm{E}-01$ & $2.48 \mathrm{E}+01$ \\
\hline $2.78 \mathrm{E}-03$ & $8.39 \mathrm{E}-02$ & $1.16 \mathrm{E}+01$ \\
\hline $2.39 \mathrm{E}-03$ & $5.31 \mathrm{E}-02$ & $5.61 \mathrm{E}+00$ \\
\hline $2.03 \mathrm{E}-03$ & $2.97 \mathrm{E}-02$ & $2.53 \mathrm{E}+00$ \\
\hline $1.74 \mathrm{E}-03$ & $1.67 \mathrm{E}-02$ & $1.39 \mathrm{E}+00$ \\
\hline
\end{tabular}

Coronal Hole

\begin{tabular}{|c|c|c|c|c|c|c|c|}
\hline $\mathrm{FOV}\left[{ }^{\circ}\right]$ & Height $\left[\mathrm{R}_{\odot}\right]$ & $30.4 \mathrm{~nm}$ & $121.6 \mathrm{~nm}$ & $\begin{array}{l}590-650 \mathrm{~nm} \\
\text { one exp of } \mathrm{pB}\end{array}$ & $30.4 \mathrm{~nm}$ & $121.6 \mathrm{~nm}$ & $\begin{array}{l}590-650 \mathrm{~nm} \\
\text { one exp of } \mathrm{pB}\end{array}$ \\
\hline 1.50 & 2.82 & 4.66E-03 & $6.08 \mathrm{E}-02$ & $7.50 \mathrm{E}+00$ & $1.57 \mathrm{E}-04$ & $2.37 \mathrm{E}-03$ & $3.22 \mathrm{E}-01$ \\
\hline 1.80 & 3.38 & $4.90 \mathrm{E}-03$ & 7.82E-02 & $9.98 \mathrm{E}+00$ & $3.10 \mathrm{E}-04$ & $2.26 \mathrm{E}-03$ & $3.65 \mathrm{E}-01$ \\
\hline 2.10 & 3.94 & $3.10 \mathrm{E}-03$ & $6.18 \mathrm{E}-02$ & $5.39 \mathrm{E}+00$ & $3.63 \mathrm{E}-04$ & $1.01 \mathrm{E}-03$ & $1.54 \mathrm{E}-01$ \\
\hline 2.40 & 4.51 & $2.66 \mathrm{E}-03$ & $4.28 \mathrm{E}-02$ & $3.80 \mathrm{E}+00$ & $3.38 \mathrm{E}-04$ & $2.82 \mathrm{E}-04$ & $9.51 \mathrm{E}-02$ \\
\hline 2.70 & 5.07 & $2.05 \mathrm{E}-03$ & 2.84E-02 & $2.91 \mathrm{E}+00$ & $2.82 \mathrm{E}-04$ & $5.96 \mathrm{E}-05$ & $4.80 \mathrm{E}-02$ \\
\hline 3.00 & 5.64 & $1.46 \mathrm{E}-03$ & $1.76 \mathrm{E}-02$ & $1.74 \mathrm{E}+00$ & $2.18 \mathrm{E}-04$ & $1.13 \mathrm{E}-05$ & $2.27 \mathrm{E}-02$ \\
\hline
\end{tabular}

Table 6 Estimated imaging countrates (count/s/pixel) at Solar minimum at $0.5 \mathrm{AU}$. 
The expected countrates for the EUV/UV spectrographic path are given in Table 7 (at 0.28 AU) and Table 8 (at $0.5 \mathrm{AU}$ ).

Streamer

\begin{tabular}{|c|c|c|c|c|c|}
\hline FOV $\left.{ }^{\circ}\right]$ & Height $\left[\mathrm{R}_{\odot}\right]$ & $30.4 \mathrm{~nm}$ & $121.6 \mathrm{~nm}$ \\
\hline 1.50 & 1.58 & $1.33 \mathrm{E}-02$ & $7.68 \mathrm{E}-01$ \\
\hline 1.80 & 1.89 & $1.56 \mathrm{E}-02$ & $9.16 \mathrm{E}-01$ \\
\hline 2.10 & 2.21 & $1.21 \mathrm{E}-02$ & $7.41 \mathrm{E}-01$ \\
\hline
\end{tabular} \begin{tabular}{|c|c|c|}
\hline $5.13 \mathrm{E}-04$ & $8.40 \mathrm{Em}-02$ \\
\hline $3.00 \mathrm{E}-04$ & $6.48 \mathrm{E}-02$ \\
\hline $2.78 \mathrm{E}-04$ & $4.20 \mathrm{E}-02$ \\
\hline
\end{tabular}

Table 7 Estimated spectroscopy countrates (count/s/pixel) at Solar minimum from perihelion at 0.28 AU.

Streamer

\begin{tabular}{|c|c|c|c|}
\hline FOV $\left[{ }^{\circ}\right]$ & Height $\left[\mathrm{R}_{\odot}\right]$ & $30.4 \mathrm{~nm}$ & $121.6 \mathrm{~nm}$ \\
\hline 1.50 & 2.82 & $4.66 \mathrm{E}-04$ & $3.04 \mathrm{E}-02$ \\
\hline 1.80 & 3.38 & $4.90 \mathrm{E}-04$ & $3.91 \mathrm{E}-02$ \\
\hline 2.10 & 3.94 & $3.10 \mathrm{E}-04$ & $3.09 \mathrm{E}-02$ \\
\hline
\end{tabular}

Table 8 Estimated spectroscopy countrates (count/s/pixel) at Solar minimum at 0.5 AU.

\section{Coronal Hole}

\begin{tabular}{|l|l|}
\hline $30.4 \mathrm{~nm}$ & $121.6 \mathrm{~nm}$ \\
\hline $1.57 \mathrm{E}-05$ & $1.19 \mathrm{E}-03$ \\
\hline $3.10 \mathrm{E}-05$ & $1.13 \mathrm{E}-03$ \\
\hline $3.63 \mathrm{E}-05$ & $5.07 \mathrm{E}-04$ \\
\hline
\end{tabular}

The spectral resolution corresponds to the minimum spectral resolution element of 4-pixels (i.e., $0.018 \mathrm{~nm}$ at $30.4 \mathrm{~nm}$ and $0.072 \mathrm{~nm}$ at $121.6 \mathrm{~nm})$, for the slit closest to the disk $\left(1.5^{\circ}\right)$ and for the intermediate slit $\left(1.8^{\circ}\right)$. For the external slit $\left(2.1^{\circ}\right)$, the spectral resolution is a factor of two lower $(0.036 \mathrm{~nm}$ at $30.4 \mathrm{~nm}$ and $0.144 \mathrm{~nm}$ at $121.6 \mathrm{~nm})$. The spatial resolution corresponds to 2 pixels $(45 \mathrm{arcsec})$ for the slit closest to the disk $\left(1.5^{\circ}\right)$, to 6 pixels $(\sim 2$ arcmin) for the intermediate slit $\left(1.8^{\circ}\right)$ and to more than 8 pixels $(\sim 3 \mathrm{arcmin})$ for the external slit $\left(2.1^{\circ}\right)$ [7]. Taking into account that the detectors' pixels will be binned to match these spatial and spectral resolutions, the estimated countrates reported in Tables Table 5Table 6Table 7Table 8, meet the science requirements summarized in the Traceability Matrix (cfr. Table 1).

\section{CONCLUSION}

METIS, the "Multi Element Telescope for Imaging and Spectroscopy", is a coronagraph selected by the European Space Agency to be part of the payload of the Solar Orbiter mission to be launched in 2017. The unique profile of this mission will allow 1) a close approach to the Sun (up to 0.28 A.U.) thus leading to a significant improvement in spatial resolution; 2) quasi co-rotation with the Sun, resulting in observations that nearly freeze for several days the large-scale outer corona in the plane of the sky and 3) unprecedented out-of-ecliptic view of the solar corona.

METIS. the Multi Element Telescope for Imaging and Spectroscopy. is one of the remote-sensing instruments of Solar Orbiter consisting in an innovative coronagraph for the study and overall characterization of the solar corona. METIS is an inverted-occultation coronagraph that by a combination of multilayer mirror coatings and spectral bandpass filters, will image the solar corona in three different wavelengths: in visible light, between 590 and $650 \mathrm{~nm}$, and in the two Lyman- $\alpha$ lines of neutral hydrogen (HI at $121.6 \mathrm{~nm}$ ) and of singly-ionized helium (HeII at $30.4 \mathrm{~nm}$ ). These measurements will allow a complete characterization of the three most important plasma components of the corona and the solar wind, that is, electrons, hydrogen, and helium. 


\section{ACKNOWLEDGMENT}

This work has been supported by the Italian Space Agency under contract number I/043/10/0. The Authors would like to thank the team of the METIS industrial Prime Contractor THALES Alenia Space - Italy for their support.

\section{REFERENCES}

[1] Muller. D.. Marsden. R.G.. StCyr. O.G.. Gilbert. H.R., the Solar Orbiter Team, "Solar Orbiter Exploring the Sunheliosphere connection". Solar Phys. In press (2012).

[2] Antonucci. E.. Fineschi. S. Gardiol. G.. Noci. G.. Romoli. M.. Naletto. G.. Tondello. G..Zatterin. M. Malvezzi. M.. Cesare. S., "Ultraviolet and Visible-light Coronograph for the Solar Orbiter Mission". SPIE 4139. p. 26. (2000).

[3] Antonucci. E.. Abbo. L.. Dodero. M.A., "Slow Wind and Magnetic Topology in the Solar Minimum Corona in 1996-1997'. A\&A. 435. 699 (2005).

[4] Fineschi. S., Korendyke. C.. Moses. J.D.. Thomas. R.T., "Solar ultraviolet spectro-coronagraph with toroidal varied line-space (TVLS) grating". SPIE 5487. 1165 (2004).

[5] Fineschi. S.; "Inverted-COR: Inverted-Occultation Coronagraph for Solar Orbiter"; OATo Technical Report Nr 119 (2009). www.oato.inaf.it/biblioteca/pdf/TechRep119 Fineschi.pdf

[6] Fineschi.. S., "Novel Optical Designs for Space Coronagraphs: inverted occulters and Lyot-stops". Proc. ICSO 2010 - Rhodes (2010). http://congrex.nl/icso/Presentations\%20Done/Session\%205b/01_Fineschi.pdf.

[7] Fineschi. S., et al.. "METIS: a novel coronagraph design for the Solar Orbiter mission”. SPIE 8443-127 (2012).

[8] Landini. F., et al.; “Optimization of the occulter for the Solar orbiter/METIS coronagraph". SPIE $8442-77$ (2012)

[9] Antonucci. E.. Dodero. M-A.. Giordano. S., "Fast Solar Wind Velocity in a Polar Coronal Hole during Solar Minimum". Sol. Phys.. 197. 115 (2000).

[10] Kohl. J.L. et al., "First Results from the SOHO Ultraviolet Coronagraph Spectrometer". Sol. Phys.. 175.613. (1997)

[11] Telloni. D.. Antonucci. E.. Dodero. M.A., "Outflow Velocity of the $O^{+5}$ Ions in Polar Coronal Holes out to 5 R $\odot$ ". A\&A. 472.299 (2007).

[12] Ventura. R.. Spadaro. D.. Cimino. G.. Romoli. M., "Streamers and Adjacent Regions Observed by UVCS/SOHO: a Comparison between Different Phases of Solar Activity". A\&A. 430.701 (2005)

[13] Corso. A.J.. et al., "Capped Mo/Si multilayers with improved performance at $30.4 \mathrm{~nm}$ for future solar missions". Optics Express 19(15). 13963-13973. (2011).

[14] Fineschi. S.. et al., "KPol: liquid crystal polarimeter for K-corona observations from the SCORE coronagraph". SPIE. 5901. 389-399. (2005).

[15] Capobianco. G.. et al., "Electro-optical polarimeters for ground-based and space-based observations of the solar K-corona”. SPIE 8450-146 (2012).

[16] Crescenzio. G.. et al., "Imaging polarimetry with the METIS coronagraph of the Solar Orbiter". SPIE 8443-129 (2012).

[17] Bai. Y., “Teledyne Imaging Sensors: Silicon CMOS imaging technologies for x-ray. UV. visible and near infrared". SPIE. 7021-01. (2008).

[18] Loose. M. et al., "SIDECAR ASIC control electronic on a chip". Scientific Detectors for Astronomy 699-706. (2005).

[19] Uslenghi. M.. et al.; “A prototype of the UV detector for METIS on Solar Orbiter". SPIE 8443-128 (2012)

[20] Focardi. M.. et al., "The main power and processing unit for the METIS coronagraph aboard the Solar Orbiter Space Mission”. SPIE 8442-169 (2012).

[21] Siegmund. O., et al.., "Ultraviolet quantum detection efficiency of potassium bromide as an opaque photocathode applied to microchannel plates". Appl. Opt. 26-17. 360 (1987). 